\title{
'I want to be heard and seen': the visualization of EFL students' voices through story narratives and interactive theatre
}

\author{
Souad Smaili \\ School of the Arts \\ The University of Northampton, UK. \\ Waterside Campus NN1 5PH.
}

\begin{abstract}
This study was conducted at a university in Algeria. It explores the language voices and self-positioning amongst students who study English as a foreign language (EFL), through introducing an innovative teaching method that includes the process of narrating personal life experiences, turning those experiences into a scenario and performing it onstage using interactive theatre. As the voice of the learner is crucial in the classroom to break the walls of anxiety and lack of investment, to promote self-positioning and agency, and to allow the student to participate in his/her desired imagined community, I was concerned about the teaching and learning situation at the department of English where this study took place. The current situation revealed that most of the students fear to speak, but wish to become good language users and be seen by others. This has driven me towards asking the questions of what voices can they develop in theatre, and what aspects from their experiences define those voices. I ran a theatre course where 19 EFL students participated. I used thematic analysis strategy to analyse the data collected from this study. The findings revealed multiple voices that are defined by the participants' experiences in both their social and academic contexts.
\end{abstract}

Keywords: EFL students, language voices, self-positioning, agency, investment.

\subsection{Introduction}

The Algerian English teaching reforms at all educational stages first applied several teaching methods that were teacher-centred to ensure good quality teaching. When those old methods did not succeed to boost the level of English students, a shift to learner-centred approach has been considered (Benadla, 2012).This latter focuses on the students' authentic experiences that are integrated in the classroom activities. Recent educational reforms integrated technology in the teaching process, such as using videos in the classroom. However, these methods still do not help the learners to become agents and promote change in learning. The voice of the learner is not encouraged and his/her language investment is not present (Guerza, 20015). Miltra (2006) has pointed out the importance of enhancing the learners' voices in both ESL and EFL classrooms. Students should be capable of providing their opinions (i.e. voices) and express their needs and desires in the classroom. This is what shapes their voices (Prior, 2001). This enables them to promote change in learning, which is referred to as 'agency'(Vetter \& Schieble, 2016). Achieving these needs requires an appropriate space for students to express themselves. When this space becomes available for students, they can start developing their ideas, interacting with one another, developing self-respect, feeling empowered, and developing their agentic selves (Ranson, 2000; Miltra, 2006). This interaction is sometimes limited in the Algerian EFL classrooms where teachers focus on delivering the material and their course syllabus on time. More social interaction is needed. This is why I proposed an innovative method of interactive theatre to the department of English at this university. It aims at grouping EFL learners of different levels in the classroom and offering them an imagined space to narrate their personal experiences and perform them onstage. This activity is interactive and facilitates the process of investment in the target language learning (see Norton, 2000). This may lead to developing the language voices of the students and empowering them in learning. This study addresses the concept of language voices and their development. The study also identifies the types of language voices that the participants revealed.

\subsection{Review of literature}

Similar research studies conducted in the Algerian context (Hamzaoui,2006;Mokhtaria, 2012; Guerza, 2015) did not tackle the issue of students' voices in both writing (academic and reflective) and performance, and did not explore the use of interactive theatre as an innovative way to teach the productive skills (speaking and writing). For Instance, Hamzaoui (2006) looked at ways of developing Algerian EFL students' narrative and cognitive capacities through investigating their stories written in the three languages: English, French and Arabic. However, she did not explore the students' voices and self-empowerment in those samples, and how they can be enhanced via interactive theatre. Furthermore, the aspects from the students context that influence their language voices such as religion, gender and the social environment surrounding the students have not been studied. 


\subsubsection{Theatre as an innovative approach in education}

Experts in the use of drama in teaching languages (Booth, 2003; Boudreault, 2010; Bolton, 2014; Zatzman, 2003) praise the benefits of integrating drama and theatre in education. Bolton (2014) has developed the term 'interactive theatre' and implemented it in higher education. In her research findings, Bolton recommend the use of this approach mainly to teach learners of foreign languages as it increases their social interaction, vocabulary learning, critical-thinking and imagination (Bolton,2014;Pinkert, 2005).Theatre makes students speak and articulate their voices to others. This offers them a space to develop themselves, their identities and become agents in learning (Zatzman, 2003). It pushes the students to use their memory and recall experiences from real life as well as from their past (Thompson, 2003; Zatzman, 2003), but also it encourages them to imagine other situations and perform them collectively; as Tait (2002) states, theatre provides individuals with a 'social space', where they can change their emotions into imagined images improvised for the audience. Another crucial aspect of theatre is that it makes the actor's feelings and thoughts observable to others which grant him/her power onstage (Zatzman, 2003).

\subsubsection{Voice, agency and investment in language learning}

Prior (2001) claims that the individual is surrounded by multiple voices that come from his/her culture such as those of family, neighbours, friends, school, workplace. Other factors are places where people perform their religious practices, or those of any domain where the person builds his/her knowledge, relating to age, childhood, and race. These multiple voices emanate from the person into his/her social/cultural contexts. Encouraging learners to write stories/experiences from their social context (Lave and Wenger, 1981) and perform them onstage might help in developing their voices, identities, and make them agents who invest in target language teaching (Norton, 2000). It is this investment that would also help them to participate in the different imagined communities that they intend to be part of (Norton, 2000). In other words, investment is the rope that links identity, voices, imagined communities, and legitimacy to language learning (Liu \& Tannacito, 2013). Language voices reveal the selfpositioning and agency of the person in the sociocultural context (Prior, 2001).

In this study I focused on the productive skills, that is writing (stories) and speaking (oral performance onstage) because both speaking and writing reveal the inner self of individuals and the way they represent themselves and their voices. These voices are dynamic and multiple (Ivanic \& Camps, 2001). It is important to integrate the learners' experiences that encourage the inclusion of their own culture in learning, and also allow them to access the target language culture or imagine it in learning. Matsuda (2001) pointed out the above view that voice is multiple and that it is linked not just to the target language culture but to the individual own culture too. For example, peoples' clothes, laugh, way of walking, way of staring at others in the eye, their views of others, are all aspects that help others identify the social group or culture to which they belong. In other words, they show their self- positioning and shape who they are, thanks to the image they present of themselves in their social activities (2001). Self-positioning can be seen in the different words, vowels and pronouns the person uses in his/her social interactions. I believe that interactive theatre as a teaching and learning method might bring students selfpositioning and promote language voices development and students agency.

Broadly speaking, voice defines the narrators' own standpoint on specific subjects, which is empowered through his/her 'self-authority' or 'presence', and most of the time by vigorously using the personal pronoun 'I' to show power in a piece of writing(2001). Ivanic and Camps(2001) also argue that the uses of pronouns such as 'she', 'he', and 'they' reveal the self-positioning of the writer/speaker and may enhance social identity construction. Ivanić and Camps (2001) conducted a study with six Mexican postgraduate students in the UK to look at their self-positioning and identities in writing. Their analysis showed that the participants developed three types of positioning: 'ideational positioning', in which the writer talks about a particular subject in his/her story; 'interpersonal positioning', which can be found in the writer's interaction with others in the story; 'textual positioning', in which he/she narrates the story focussing on the format of his/her piece of writing. Ivanic and Camps (2001) found that the construction of identities and voices in those texts results from these three 'macro functions' or positioning in language.

\subsection{Research procedures, analysis and results}

\subsubsection{Method of Analysis}

This study is qualitative and it deals with learners' narratives and performances. It adopted inductive thematic analysis (Braun \& Clarke, 2006) to analyse the data collected from 19 EFL participants who study in the department of English at the university. These participants were selected through the combination of purposive and opportunity sampling. For this paper, I focus on the aspect of voice and the findings that emerged in relation to it. For this paper, I selected chunks of voices of six participants as an illustration to present and discuss the findings. 


\subsubsection{Results}

Analysing the participants' narratives, scripts and their interviews, I came up with four types of voices, which I define below:

\subsubsection{Cognitive voice}

Most of the participants mentioned that the theatrical course and activities increased their critical thinking, imagination and analytical abilities. Two of the participants, Jaja and Kahina (the students' names are pseudonyms), revealed their awareness towards the change theatre brought to them, compared to the teaching methods and the content of the material they are learning which do not help them to boost their creativity and imagination and which restrict their chances to speak or write what they want. They noted:

I think that most English students have a weakness in our essays and writing like in coherence and the content because we did not have much practice. Even the methods were not good. The teachers were just giving us the rules while it is not to write about a topic or follow a rule. If they gave us to write a free topic I choose myself and then take this essay and see the point where I am not perfect enough and correct it. (TRANS10: Jaja)

I like sharing my stories with others. Interaction is very important but unfortunately this is what lacks in our university, but I could experience it in this course. I could practice my English. Teachers always underestimate our capacities and tell us you cannot speak like natives, but I am sure I can...if we practice in a more motivating space such as theatre others can see us and listen to our stories....we can also speak like native speakers all comes via practice. (TRANS11: Kahina)

Another participant Bilal pointed out that the theatrical course allowed him to evaluate his skills and cognitive capacities, as for example being able to use his imagination onstage or in writing. Bilal mentioned in the interview that narrating his personal experiences helped him to review them again from an adult point of view, and to know what was good/bad in them compared to when he lived them for the first time. In other words, this might be an opportunity for him to bring a narrative voice where evaluation, criticism, awareness and imagination were present. He stated that:

It is really improving, when you write about a previous experience. It is okay you lived it, but when you write about it like you are living it for another time and like you are analysing this experience from an adult or grown up perspective as when you lived it before you could not analyse it... it is like living something I did not have the chance to live it. It is new for me and here comes the creativity it is to live and produce something new that I did not live before. The performing on stage was surrounded with my imagination and critical thinking. (TRANS 16: Bilal)

\subsubsection{Emotional voice}

According to the participants the course allowed them to express their emotions that played a part in what they have become 'students of English'. For example, Kiki revealed her sadness because of the death of her father, but she considered that this was a reason for her success in her learning journey. Kiki mentioned:

A tear fell upon my cheek but neither tears nor words can express my sadness, my grief was deep, I lost a dad; I lost a house leader; I lost a protector ...but now I feel proud that I am studying at university and I am sure you will be happy when you hear that....My mum encouraged me a lot to succeed and now I am about to become an English teacher just to make you proud... (TRANS17: KIKA)

\subsubsection{Religious voice}

Some of the participants emphasized their religious self in their narratives and performances onstage. I referred to the change they want to promote either in their families, society or university through such religious thoughts as 'religious voices'. Thiriza revealed her religious voice in one of her stories about convincing her mother to wear the veil. The script was played out by Thiriza as the main character (religious daughter), and Manel (Thiriza's mother).Thiriza's mother did not believe that women should wear a veil. In this performance, Thiriza could articulate that religious voice and let it be heard by others. She mentioned:

Script 5: My mum against Hijab!

Thiriza: Our neighbour is wearing a veil because she knows that this is what God told women to do...

Mum: She is free, but I do not believe it is an obligation...

\subsubsection{Social voice}


This type of voice refers to the participants' negotiation of social issues they experience in their society. They turned their experiences into a theatrical play and performed onstage.

This performance allowed them to extend their sentences using English and provide their opinions regarding those social problems which they tackled in their scripts. I present an example from one of the participants' scripts below:

The husband: my wife will give birth (he raises his voice).

The wife (screaming): Please, please help me I cannot...

The receptionist (not caring): take a seat in the waiting room please.

The husband: I said that my wife will give birth, give me the wheel chair...

The receptionist: There is no wheel chair. We use them for other persons. Do you think you are the only one in this hospital?

The husband: call the midwife then.

The receptionist: they are not here they went to eat.

Another woman (Korean) in the waiting room heard the man screaming so she came to the reception.

The Korean Woman: Oh, are we in a hospital, I can't believe what I see. Oh my god in my country we do not receive patients in this way! (Script 8: This is Algeria!)

\subsection{Discussion and recommendations}

The theatrical course created a change in the EFL classroom where these participants took part. The findings of this study confirm the previous views on theatre that I mentioned in the literature section of this paper (Ranson, 2000; Miltra, 2006). In other words, the students could articulate their voices and make them heard and seen by others. The voices that were developed in the students' written experiences portrayed their cognitive thinking, such as criticising the program introduced in the department of English, evaluating one's inner self (see Bilal above), and sometimes were religious or psychological where their emotions were presented in their narratives. The voices that were identified in the findings are mostly affected by individual factors that relate to the cognitive side of the person, but they were also affected by the different experiences, interactions and positions that the participant lived in his/her social context. Thus, voice is both socially and personally driven as Prior (2001) claims. Another interesting point about the findings is that the activities that the students did in this course including narration and performing roles onstage made them powerful, and agents in learning. In other words, they could visualise their ideas and concerns to others and create change in themselves and in their peers. For instance, Kika articulated her emotional voice, but described herself as a person who made of her pain a reason to change her student life into success. This may let others to reflect on Kika's story to promote change in their lives too. Thus, I would argue that voices in language learning are affected by the socio-cultural context of the individual. Providing life to different experiences lived in such a context emphasises the learners' investment and self-positioning.

The findings also revealed that the course offered the students a space to recall events from their social context and develop them into plays using imagination. This latter played a role in the imagined community the participants formed throughout the course. As Norton (2000) noted, the teacher should encourage the students to break the walls of the classroom and live in their desired imagined community as it is through this way of learning that investment and self-positioning can happen. The findings of this study showed that this imagined space and investment could be realised through theatre and the articulation of students' voices. To conclude, I would recommend that such an innovative course should be integrated in the teaching of English to give the chance to EFL students to develop their agentic selves, voices and identities. I would also recommend more research works that can study language voices and identities in such context where intersecting historical, religious and social experiences affect learning.

\section{References}

Benadla, L. "The Competency Based Language Teaching in The Algerian Middle School: From EFL Acquisition Planning to its Practical Teaching/Learning". Arab World English Journal 3.4 (2012): 144-151. Web. 17 October 2016.

Bolton, G. and Heathcote, D. (1998). Teaching culture through drama. In: M. Byram \& M. Fleming (Eds.) .Language learning in intercultural perspective (pp.1-318). Cambridge: Cambridge University Press.

Booth, D. (2003). Towards an Understanding of Theatre for Education. In: K. Gallagher, \& D. Booth, (Eds.). How Theatre Educates: Convergences \& Counterpoints with Artists, Scholars and Advocates (pp.14-22). Toronto: University of TorontoPress.

Boudreault, C. "The Benefits of Using Drama in the EFL/ESL Classroom." The Internet TESL Journal 16.1 (2010). Web. 3 October 2016. 
Braun, V. And Clarke, V. (2006). "Using Thematic Analysis in Psychology.” Qualitative Research in Psychology 3.77 (2006): 77-101. Web. 27 April 2017.

Guerza, R. "ICT in the Algerian EFL Classrooms: An Innovative Means to Enhance Learners' Autonomy". International Journal for Infonomics 8.1(2015): 979-985. Web. 15 December 2017.

Ivanic, R. And Camps, D. "I am how I sound: Voice as self-representation in L2 writing. "Journal of Second Language Writing 10 (2001): 3-33. Web. 18 April 2018.

Liu, P. H. E., and Tannacito, D.J. "Resistance by L2 Writers: The role of racial and language ideology in imagined community and identity investment". Journal of Second Language Writing 22.4 (2013): 355-373. Web. 24 July 2017.

Matsuda, P.K. "Voice in Japanese written discourse: Implications for second language writing". Journal of Second Language Writing 10 (2001): 35-53. Web. 12 November 2017.

Miltra, D. "Increasing Student Voice and Moving Toward Youth Leadership." The Prevention Researcher 131 (2006): 7-10. Web. 6 October 2017.

Mokhtaria, L. Teaching Poetry to Second Year (LMD) EFL Students at Abou Baker Belkaid University Tlemcen. Diss. University of Tlemcen, 2012. Web. 12 December 2018.

Norton, B. Identity and Language Learning. Harlow: Longman, 2000. Print.

Pinkert, U. (2005). The concept of Theatre in Theatre Pedagogy. In: S. Schomann (Eds). Key Concepts in Theatre/Drama Education (pp. 119-123). Sense Publishers.

Prior, P. "Voices in texts, mind, and society: Sociohistoric accounts of discourse acquisition and use". Journal of Second Language Writing 10 (2001): 55-81. Web. 10 November 2017.

Ranson, S. "Recognizing the Pedagogy of Voice in a Learning Community". Educational Management and Administration 28-3 (2000): 263-279. Web. 2 January2017.

Thompson, J. (2003). 'I Will Tear You to Pieces': The Classroom as Theatre. In: K. Gallagher, \& D. Booth, D. (Eds.). How Theatre Educates: Convergences and Counterpoints (pp. 24-35). Toronto: University of Toronto Press.

Vetter, A. and Schieble, M. (2016). Positions of Power. In: A. Vetter, \& M. Schieble (Eds.). Observing Teacher Identities Through Video Analysis: Practice and Implications (pp.42-63). New York: Routledge.

Zatzman, B. (2003). The Monologue Project: Drama as a Form of Witnessing. In K. Gallagher, \&

D. Booth (Eds.). How Theatre Educates: Convergences \& Counterpoints (pp. 35-55). Toronto: University of Toronto Press. 